\title{
A (IN) VIABILIDADE DA EDUCAÇÃO E DO TRABALHO COMO INSTRUMENTOS DE RESSOCIALIZAÇÃO DE INDIVÍDUOS ENCARCERADOS
}

\author{
THE (UN) FEASIBILITY OF EDUCATION AND WORK AS INSTRUMENTS FOR THE \\ RELEASE OF JUSTICE INDIVIDUALS
}

\author{
Renato Santiago Quintal \\ Doutor em Ambiente e Desenvolvimento \\ Escola Naval - EN \\ Rio de Janeiro, Rio de Janeiro - Brasil \\ rsantiago79@hotmail.com \\ Carlos Francisco Simões Gomes \\ Doutor em Engenharia de Produção \\ Universidade Federal Fluminense - UFF \\ Niterói, Rio de Janeiro - Brasil \\ cfsg1@bol.com.br
}

\begin{abstract}
Resumo: A pesquisa vislumbra a possibilidade de se estabelecer uma conexão entre educação, trabalho e o plano jurídico, debruçando-se especificamente sobre o sistema prisional. O seu objetivo é empreender a análise da viabilidade da educação e do trabalho como instrumentos de ressocialização de indivíduos encarcerados na região metropolitana do Rio de Janeiro. O corrente estudo fundamentou-se na abordagem da pesquisa qualitativa. Para alcançar o objetivo proposto, foram selecionados os seguintes recursos metodológicos, a saber: pesquisa bibliográfica; análise de documentos escritos, em especial, dispositivos legais e normativos. Foram consultados livros, artigos, teses, dissertações e informações disponíveis em portais administrados por órgãos públicos e privados. Supletivamente, este trabalho contou com os aportes das pesquisas empreendidas por Julião (2007, 2009 e 2012). Vislumbra-se que a modesta contribuição desta pesquisa seja a adoção de uma abordagem interdisciplinar. Os apontamentos realizados ao longo da pesquisa evidenciam que a educação e o trabalho ainda não se configuram como instrumentos efetivos de ressocialização de apenados. Espera-se que o presente estudo possa favorecer as discussões sobre ressocialização de indivíduos encarcerados a partir das ações empreendidas pela educação e pelo trabalho no ambiente prisional, permitindo a articulação entre profissionais das searas da administração penitenciária, da educação e da sociedade civil.
\end{abstract}

Palavras-chave: execução penal; trabalho e educação em prisões; ressocialização.

\begin{abstract}
The research envisions the possibility of establishing a connection between education, work and the legal plane, focusing specifically on the prison system. Its objective is to undertake the analysis of the feasibility of education and work as instruments of resocialization of individuals imprisoned in the metropolitan region of Rio de Janeiro. The current study was based on the qualitative research approach. To reach the proposed objective, the following methodological resources were selected, namely: bibliographic research; Analysis of written documents, in particular legal and regulatory provisions. Books, articles, theses, dissertations and information available on portals administered by public and private agencies were consulted. Supplementarily, this work counted on the contributions of the researches undertaken by Julião $(2007,2009$ and 2012). It is envisaged that the modest contribution of this research is the adoption of an interdisciplinary approach. The notes made throughout the research show that education and work are not yet configured as effective instruments for the resocialization of distressed people. It is hoped that the present study may favor discussions about the resocialization of individuals incarcerated from the actions taken by education and work in the prison environment, allowing the articulation between professionals in the prison administration, education and civil society.
\end{abstract}

Keywords: criminal enforcement; prison work and education; resocialization.

Para citar - (ABNT NBR 6023:2018)

QUINTAL, Renato Santiago; GOMES, Carlos Francisco Simões. A (in) viabilidade da educação e do trabalho como instrumentos de ressocialização de indivíduos encarcerados. Eccos - Revista Científica, São Paulo, n. 57, p. 1-19, e8905, abr./jun. 2021. Disponível em: https://doi.org/10.5585/eccos.n57.8905. 


\section{Introdução}

Este artigo estuda a possibilidade de se estabelecer uma conexão entre as searas da educação e do trabalho e o plano jurídico, debruçando-se especificamente sobre o sistema prisional. Nesse contexto, compreende-se que é primordial revisitar as áreas de conhecimento do direito processual penal e da sociologia da educação e do trabalho.

Objetiva-se empreender a análise da viabilidade da educação e do trabalho como instrumentos de ressocialização de indivíduos encarcerados na região metropolitana do Rio de Janeiro. Sob esse prisma, emerge a seguinte questão de pesquisa: Em que medida a educação e o trabalho possibilitam a ressocialização daqueles indivíduos?

Recentemente, o sistema penitenciário tem sido enxergado pelos governantes como uma autêntica "caixa-preta". Muito se discute, mas pouco se conhece no que diz respeito a sua genuína realidade. Um conjunto expressivo de cientistas vem se debruçando sobre as questões afetas à violência e à criminalidade. Contudo, verifica-se a existência de um número restrito de pesquisas voltadas à problemática da prisão (JULIÃO, 2007). Sabe-se que "não é possível compreender o movimento da criminalidade urbana ignorando o funcionamento das agências de controle e repressão ao crime" (RAMALHO apud JULIÃO, 2007, p.30). Progressivamente, constata-se a premência do incremento do debate e da pesquisa acerca do tema com enfoque interdisciplinar no âmbito de institutos de pesquisa e universidades, viabilizando subsídios tangíveis para a formulação de políticas públicas (JULIÃO, 2007). Profissionais de diversas áreas - direito, educação, serviço social e ciências econômicas - têm investigado essa temática e formulado as mais distintas propostas.

Nesse contexto, espera-se que o resultado da pesquisa possa favorecer as discussões acerca dos reflexos da educação e do trabalho no ambiente prisional, permitindo a avaliação da efetivação das práticas de promoção da ressocialização de indivíduos encarcerados. Adicionalmente, vislumbra-se que o presente trabalho possa ser desdobrado em questionamentos e investigações futuras.

O corrente estudo fundamentou-se na abordagem da pesquisa qualitativa. Para alcançar o objetivo proposto, foram selecionados os seguintes recursos metodológicos, a saber: pesquisa bibliográfica; análise de documentos escritos, em especial, dispositivos legais e normativos. Foram consultados livros, artigos, teses, dissertações e informações disponíveis em portais administrados por órgãos públicos e privados. Supletivamente, este trabalho contou com os aportes das pesquisas empreendidas pelo Professor Elionaldo Fernandes Julião. Nessa 
conjuntura, vislumbra-se que a modesta contribuição desta pesquisa seja a adoção de uma abordagem interdisciplinar.

Espera-se que o presente estudo possa favorecer as discussões sobre ressocialização de indivíduos encarcerados a partir das ações empreendidas pela educação e pelo trabalho no ambiente prisional, permitindo a articulação entre profissionais das searas da administração penitenciária, da educação e da sociedade civil. O artigo se divide nas seguintes seções: introdução; sistema carcerário e execução penal; ressocialização de apenados: possibilidades e limitações; e considerações finais.

\section{Sistema carcerário e execução penal}

\subsection{Sistema carcerário}

Quando se vislumbra as distintas instituições da sociedade contemporânea, identificase que algumas delas são bem mais "fechadas" do que as demais. Seu fechamento ou seu cunho total é representado pela obstrução ao vínculo social com o âmbito externo e por vedações à saída as quais muitas vezes estão contempladas no arranjo físico, particularmente pelo emprego de portas cerradas, paredes elevadas, valas profundas, arames farpados, entre outros dispositivos. Esses estabelecimentos são denominados de instituições totais (GOFFMAN, 2008).

O cárcere e as outras instituições de confinamento são espaços fechados e, por conseguinte, fisicamente isolados e apartados da sociedade livre, contudo esse fracionamento é mais aparente que real, já que a prisão não faz mais do que aventar ou conduzir ao ápice padrões de organização social ou econômico que se pretende instituir ou que já se encontram em vigor na sociedade (MODONA, 2006).

O lócus prisional, desse modo, é orientado por uma condição característica de vida, com seus regramentos, procedimentos e seus símbolos distintivos, convertendo-se em um ambiente de divergência e inquietação entre os seus agentes. Sob essa perspectiva, os sujeitos se subordinam ao assentimento desses regramentos e procedimentos, no esforço de subsistir e encurtar o tempo passado na prisão. Esse arranjo de costumes, valores e normas compartilhados pelos internos se forma ao longo do processo de socialização pelo qual o indivíduo se conforma à linguagem, aos códigos, aos conhecimentos do grupo e à cultura social da corporação. Nessa circunstância, dentre o rol de atividades que são empreendidas no cárcere, convém elencar as atividades educacionais. O espaço em que se dá o ato educativo é ímpar e distinto de outros 
espaços, tais como os praticados em igreja, família, círculo de amizade, entre outros (CARVALHO; GUIMARÃES, 2013).

Carnelutti (2013, p.88) emprega uma metáfora para descrever o sistema penitenciário. Para ele, "a penitenciária é, verdadeiramente, um hospital, cheio de enfermos de espírito e não do corpo, e, alguma vez, também do corpo; mas que singular hospital!”, argumenta o referido jurista.

Os escritos de D.V. Coornhert, datados em 1567, sustentam, de forma bem semelhante àquela apresentada por Thomas Morus, no livro Utopia, que, se na Espanha cem a duzentos florins representam o valor de um escravo, os homens livres da Holanda, majoritariamente conhecedores de um ofício, tinham mais valor vivos do que mortos, e, consequentemente, o mais apropriado seria fazê-los laborar quando praticassem um delito. Nesse contexto, a forma de pensar de Coornhert (e de outros progressistas que o acompanhavam) não ficou muito tempo sem ser empreendida (SELLIN apud MELOSSI, 2006).

Traçando-se um paralelo com o contex to brasileiro, o Estado enxergava o interno como indivíduo marginal/marginalizado, o qual necessitava laborar de modo que tivesse utilidade para a sociedade, uma vez que o trabalho era considerado a dignificação da existência humana. Nesse sentido, a força de trabalho do interno começou a ser explorada. E é o arcabouço legal, que ratificava esse método de exploração e depreciação, que compelia indivíduos em penitência a trabalhar (PEREIRA, 2011).

\subsection{A execução penal}

As temáticas ligadas ao crime e ao tratamento da criminalidade permanecem em discussão nas sociedades contemporâneas, aguçando a atenção do público, dos administradores e dos legisladores (PAIVA, 2012).

A criminalidade, em diversas ocasiões, representa um desprovimento de socialização. Consequentemente, há a necessidade de que a execução penal envide esforços em contrabalancear, em cada delinquente individual, as insuficiências de seus correspondentes processos de socialização, permitindo ao condenado retornar a uma vida que se amolde à legislação, fomentando de todas as formas permitidas sua assimilação pela comunidade legal em que pertence (LEMOS; MAZZILLI; KLERING, 1998).

Em 1984, o sistema prisional apresentou novas instruções com o advento da Lei de Execução Penal (Lei n 7.210/84), a qual procurou assegurar, de forma legal, direitos aos indivíduos presos. Contudo, na prática, muitas das demandas não foram realizadas pelo Estado, 
em especial a assistência educacional que ainda não representa uma realidade na maior parte dos estabelecimentos prisionais (PEREIRA, 2011).

As atribuições assumidas pelo trabalho prisional se revestem de suma importância para a execução penal, à medida que a atenção dessa se concentra na possibilidade de ressocialização do apenado, revelando o trabalho prisional como excepcional mediador, por intermédio das demandas que lhe são inerentes, para a adaptação dos indivíduos às convenções sociais (LEMOS; MAZZILLI; KLERING, 1998).

O trabalho prisional produzido nas instituições penitenciárias obedece rigorosamente aos fundamentos do taylorismo, especialmente, pelo fato de estar direcionado ao controle dos apenados, favorecendo uma austera disciplina, sendo integralmente preceituado e institucionalizado pela Lei de Execuções Penais (LEP), a qual estabelece quem deve trabalhar e como esse trabalho necessita ser realizado (LEMOS; MAZZILLI; KLERING, 1998).

A preponderância do binômio segurança/disciplina sobre todo e qualquer projeto de ressocialização tem sido considerada como o maior dos obstáculos ao empreendimento do trabalho, da educação, da psicologia e do serviço social no interior do cárcere (PORTUGUES, 2001; SILVA, 2001). Contudo, faz-se necessário assinalar igualmente a relação de subordinação que estas ciências mantêm com as ciências jurídicas, como se representassem apêndices destas (SILVA, MOREIRA, 2012).

O Direito Penal Brasileiro encontra-se dividido em duas correntes de juristas com visões e entendimentos distintos. Uns sustentam que a resposta para pôr fim à violência encontra-se no enrijecimento da lei e na cominação de penas austeras para os mais truculentos. Outros, incrédulos de que a austeridade da pena cominada "tenha eficácia preventiva e/ou reabilitadora", argumentam que a pena de reclusão encontra-se ultrapassada como condição de reeducação (JULIÃO, 2007, p.31).

Uma terceira corrente desenvolveu-se, nos últimos anos, fortemente às margens das outras duas, especialmente em alguns países da América Latina, alegando um "direito alternativo" e condenando o ponto de vista tradicional positivista acrítico do Direito, cuja lógica se converge em "começar e findar na lei". O argumento do "direito alternativo" transcende as fronteiras do legalismo, desaprovando as razões do direito e da sociedade, e manifesta-se contra a estrutura social, recomendando outra categoria de convivência à sociedade (JULIÃO, 2007, p.31).

Com o advento da "desfederalização" do Direito Penal, o sistema carcerário, a justiça e o sistema policial encontram-se estruturados em âmbito estadual, de maneira que cada governo possui certo nível de autonomia. A efetivação de políticas públicas na seara da execução penal 
no contexto brasileiro ficou a cargo de cada unidade da federação. Por esse motivo, em função da diversidade cultural, social e econômica de cada município, verifica-se a heterogeneidade da realidade carcerária brasileira, diferenciando-se no que concerne a região, unidade da federação e unidade prisional (JULIÃO, 2007, p.33).

O sistema prisional brasileiro, a justiça e o seu sistema policial encontram-se estruturados, especialmente, em âmbito estadual, de maneira que cada governo se reveste de relativa autonomia na formulação de políticas públicas voltadas à educação escolar no ambiente prisional. Por esse motivo, em função da diversidade regional e política, a realidade prisional brasileira mostra-se heterogênea, distinguindo-se de acordo com o Estado ou, até mesmo, a unidade prisional. Nesse sentido, a aplicabilidade das normas obedece aos enredos e às particularidades em nível local (OLIVEIRA, 2013).

A perspectiva recente da educação escolar nas prisões tem evidenciado, por um lado, debilidades e carências resultantes. Por outro, a partir do arcabouço legal e das diretrizes pátrias em vigor, exibem-se possibilidades de se empreender uma política pública vinculada de forma pedagógica à execução penal (OLIVEIRA, 2013).

As pesquisas acerca da educação prisional apontam que, entre trabalhar e estudar, os internos optam por trabalhar, em função dos benefícios advindos da remissão pelo trabalho: a cada três dias de trabalho, os detentos conquistam o direito de um dia a menos no cômputo da pena, enquanto em relação aos dias estudados, a decisão cabe à autoridade judicial. Outro aspecto complicador é a ausência de maleabilidade dos horários destinados ao estudo, que, majoritariamente, são observados no período da manhã e tarde, não oportunizando a harmonização entre trabalho e educação (CARVALHO, GUIMARÃES, 2013).

Faz-se necessária a construção de uma proposta pedagógica para a execução penal no seio dos estabelecimentos prisionais, considerando-se a prática de outras atividades no cárcere, especificamente saúde, trabalho, assistência social e cultura. Essa concepção é essencial, uma vez que expressivo quantitativo de internos não levam adiante seus estudos pela impossibilidade, nessas unidades, da conciliação de mais de um afazer (OLIVEIRA 2013).

\section{Ressocialização de apenados: possibilidades e limitações}

\subsection{Sistema carcerário nacional}

Distintos países latino-americanos, dentre os quais o Brasil, têm apresentado, nos últimos anos, elevados índices de encarceramento. Recentemente, o Brasil vem exibindo índices progressivos, posicionando-se atrás unicamente da China, EUA e Rússia. Um 
quantitativo crescente de indivíduos reclusos tem sido acompanhado de um sucateamento cada vez maior do sistema prisional e, por consequência, da precarização das condições mínimas necessárias ao cumprimento dos requisitos de tutela de presos e do preconizado por convenções internacionais (JULIÃO, 2007).

Os patamares de superlotação são cabalmente surpreendentes, e as circunstâncias sanitárias, indecorosas. A violência entre os presos é algo corriqueiro e os espancamentos realizados por agentes penitenciários são frequentes. As assistências médica, jurídica e social são insuficientes e as unidades da federação não têm conseguido disponibilizar atividades de cunho laborativo, educacional e cultural aos internos (JULIÃO, 2007).

Observa-se que o sistema penitenciário se estrutura sobre a punição, como configuração real e simbólica de saída para o problema, sugerindo, na teoria, a ressocialização do apenado, supondo que a transgressão às normas esteja associada à ausência de disciplina moral para a convivência em sociedade. Nesse contexto, a pena é compreendida não somente enquanto punição, mas como elemento de reeducação do infrator (JULIÃO, 2012).

Objetivos, punição e ressocialização, evidenciados como escopo do sistema penitenciário nas sociedades atuais, estão sujeitos a críticas e são marcados por ações e metas totalmente contraditórias, em face da impossibilidade de se regenerar punindo. Nem mesmo os agentes operadores da execução penal creem na perspectiva de ressocialização do detento. Observam, dessa forma, métodos diversos que habitualmente frustram a expectativa de realização de atividades de caráter pedagógico para os internos (JULIÃO, 2012).

A crença na possibilidade do retorno ao convívio humano, de deixar de usar o uniforme de interno, de retomar a postura de homem livre e de reconquistar o seu espaço na sociedade, é o combustível que alimenta o encarcerado e o propósito da sua vida. Com a saída do cárcere, o processo termina, mas não a pena, no que diz respeito ao sofrimento e ao castigo. O egresso do cárcere acredita não ser mais aprisionado, mas as pessoas não o veem assim. Para elas, ele será sempre encarcerado, quando muito ex-encarcerado (CARNELUTTI, 2013).

A instituição da LEP não restaura direitos, porém revela que os detentos, durante todo o transcurso de vigência do direito penal e das ciências penais, não recebem o adequado tratamento. O amparo previsto nessa legislação não salvaguarda a essência da sua recuperação. Sobrevém nos dias atuais a premente necessidade de atualização do Código Penal em vigor e o efetivo cumprimento da LEP. A efetividade dessa legislação com certeza alteraria o panorama carcerário. Os ordenamentos jurídicos exauriram a descrença na eficácia legal e a penalização acentuada do preso apresentaria uma execução justa. O que se identifica atualmente é a 
divergência entre a legislação e o cárcere, resultando no colapso do sistema penitenciário brasileiro (RIBEIRO, 2011).

Sob esse prisma, é possível assinalar que as unidades da federação que mais apresentam apenados trabalhando no Brasil são as seguintes: Santa Catarina, Rondônia, Rio Grande do Sul, Piauí e Bahia. Por outro lado, os estados que menos ostentam apenados trabalhando são: Ceará, Rio de Janeiro, Pernambuco, Paraná, Espírito Santo, Minas Gerais, Rio Grande do Norte e Paraíba (JULIÃO, 2012).

No plano teórico, especialmente quando se considera o preconizado na LEP, há diferenciação quanto ao público-alvo e aos propósitos de cada unidade penal. Nesse contexto, as penitenciárias estão voltadas aos condenados à pena de reclusão, em regime fechado. Os presídios destinam-se ao recebimento dos internos que se encontram em cumprimento de prisões preventivas ou com sentença que não foi transitada em julgado. A colônia agrícola, industrial ou similar reserva-se ao cumprimento da pena em regime semiaberto. A casa do albergado encontra-se voltada ao cumprimento de pena privativa de liberdade em regime aberto, bem como da pena de limitação de fim de semana. O centro de observação tem como propósito empreender exames gerais e criminológicos. O hospital de custódia e tratamento psiquiátrico é destinado aos inimputáveis e semi-imputáveis. A cadeia pública encontra-se voltada ao recolhimento do preso provisório. Por fim, o patronato está associado à prestação da assistência aos albergados e aos egressos (JULIÃO, 2012).

\subsection{Diagnóstico do sistema carcerário fluminense}

Condicionando-se à LEP, e com o propósito de complementá-la, no ano de 1986 foi assinado o Decreto $\mathrm{n}^{\circ}$. 8.897, que regulamenta o sistema penal do Estado do Rio de Janeiro (JULIÃO, 2007).

Segundo informações apresentadas pelo Ministério da Justiça, atinentes ao ano de 2007, extraídas da pesquisa de Julião (2009), o Rio de Janeiro é o estado que mais encarcera em números absolutos no Brasil, apresentando o quantitativo de 26.523 presos - o que representa 6,28\% da população carcerária nacional -, sendo 1.463 o número de mulheres. Nesta classificação, o estado do Rio de Janeiro fica atrás apenas de São Paulo e Minas Gerais que detêm, respectivamente, 153.056 (36,23\% da população nacional carcerária) e 37.354 presos (8,85\% da população nacional carcerária). Nesse contexto, os três estados ao todo encarceram mais de $51,36 \%$ da população nacional carcerária.

O sistema penitenciário do estado do Rio de Janeiro apresenta a seguinte estrutura, a saber: 14 penitenciárias; 07 presídios; 06 casas de custódia; 05 institutos penais; 01 colônia 
agrícola; 07 hospitais de custódia e tratamento; 01 patronato (Patronato Margarino Torres); 01 casa do albergado; 01 unidade materno infantil; e 01 fundação pública (Fundação Santa Cabrini) (JULIÃO, 2009).

A pesquisa de Julião (2012) assinala que o nível educacional dos presos não se diferencia muito do nível da população de forma genérica. Ademais, o índice de analfabetismo é menor. Algumas indagações podem apontar indícios: (1) estaria esse fato relacionado à escolarização no interior dos estabelecimentos prisionais? (2) essa circunstância estaria associada à essência mais urbana do preso e/ou à preponderância do analfabetismo nas áreas rurais? De toda forma, os dados enfraquecem a crença de que os presos representam um grupo de baixo nível educacional quando comparado com a população em geral.

Julião (2012) reconhece que a constituição racial da população das unidades da federação é bastante heterogênea. Na conjuntura fluminense de distribuição da população carcerária por etnia, aquele autor aponta que 39,25\% são brancos, $21,83 \%$ são pretos e $38,05 \%$ são pardos.

Inevitavelmente, há uma justificativa de cunho sociológico para os elevados índices de indivíduos pobres e negros internos no sistema carcerário pátrio: os primórdios da formação social e econômica brasileira. Sem a compreensão desses rudimentos, os números somente configuram as implicações desse processo e estimulam políticas públicas que não enfrentam as razões: a pobreza profunda, a exiguidade de possibilidades educacionais, formativas, laborais etc. (PEREIRA, 2011).

A diminuta presença numérica feminina no sistema prisional tem ocasionado a invisibilização das carências desse grupo minoritário no âmbito das políticas penitenciárias as quais, geralmente, conformam-se aos arquétipos propriamente masculinos (JULIÃO, 2012).

Quanto ao percentual de internos em programas de laborterapia no contexto fluminense, verifica-se que somente 7,29\% dos internos encontram-se ocupados profissionalmente, ao passo que a média nacional é de 23,95\%. Destes, 23,7\% participam de trabalho externo; a maioria, 76,26\%, encontra-se envolvida em atividades no interior das unidades prisionais, especialmente apoiando os estabelecimentos. São dados mais expressivos do que aqueles verificados em âmbito nacional, ratificando a hipótese de que os internos efetivamente passaram a complementar a força de trabalho das unidades prisionais, substituindo, em algumas situações, os profissionais do próprio sistema penitenciário, especialmente em atividades administrativas e de manutenção (JULIÃO, 2012).

Nesse sentido, os dados apresentados evidenciam que o sistema penitenciário brasileiro não vem acatando ao preconizado na LEP, cujo texto estabelece que todos os internos teriam 
que estar exercendo atividade profissional de caráter instrutivo e formativo. Estes elementos confirmam a suspeita de que, com o advento do parco número de profissionais operando no sistema penitenciário, particularmente nas searas administrativas e de manutenção, os internos do sistema carcerário passaram a complementar a força de trabalho das unidades penais, chegando, em determinadas situações, a repor trabalhadores do próprio sistema penitenciário. Nesse contexto, a atividade laborativa para os internos no âmbito da política de execução penal, de forma resumida, deixa de se revestir de um caráter essencialmente pedagógico, como prescreve a Lei de Execução Penal, para atender às demandas referentes à continuidade do próprio sistema (JULIÃO, 2012).

Embora a norma esteja em vigor, na conjuntura prisional verifica-se que o trabalho é empregado de forma prioritária em prejuízo das atividades educativas. No entanto, o trabalho é assimilado pelos internos como um jeito de aproveitar o tempo e, em determinadas situações, como uma estratégia de auferir remuneração apropriada (OLIVEIRA 2013).

\subsection{Educação e trabalho como instrumentos de ressocialização: discursos controversos}

A essencial atribuição da educação, tanto na escola como no cárcere, é aprimorar as potencialidades dos indivíduos para formular decisões expeditas em cenários tão contraditórios quanto aqueles encontrados na sociedade contemporânea em permanente mudança (CARVALHO; GUIMARÃES, 2013).

O direito à educação similarmente é denominado direito de síntese, ao proporcionar e fomentar a garantia dos demais direitos. Além disso, esse direito está contemplado em variados documentos internacionais, em especial:

Declaração Mundial sobre Educação para Todos (artigo $1^{\circ}$ ); Convenção Internacional
sobre os Direitos da Criança (parágrafo $1^{\circ}$, art. 29); Convenção contra a Discriminação
no Ensino (artigos $3^{\circ}, 4^{\circ}$ e $5^{\circ}$ ); Declaração e Plano de Ação de Viena (parte no 1 ,
parágrafo 33 e 80); Agenda 21 (capítulo 36); Declaração de Copenhague
(compromisso no 6); Plataforma de Ação de Beijing (parágrafos 69, 80, 81 e 82);
Afirmação de Aman e Plano de Ação para o Decênio das Nações Unidas para a
Educação na Esfera dos Direitos Humanos (parágrafo $2^{\circ}$ ) (OLIVEIRA 2013, p.958).

É manifesto no plano teórico que a educação prisional ao indivíduo sob tutela do sistema penitenciário brasileiro passa pelo direito à assistência educacional, o qual é regido nos dias atuais pelas legislações pátrias, notadamente: Carta Magna de 1988; a Lei de Execução Penal; os regulamentos penitenciários de âmbito estadual, aderentes à LEP; as Resoluções do Conselho Nacional de Política Criminal e Penitenciária; a Lei de Diretrizes e Bases da Educação Nacional; e normatizações de cunho internacional (VASQUEZ, 2011). 
A investigação da trajetória afeta a jovens e adultos inseridos no sistema carcerário e da relação de vida na prisão com educação e trabalho tem se mostrado um nicho de pesquisa recente na área da educação e das ciências sociais. Não existem muitos estudos, mas é possível afirmar que há um conjunto reduzido, mas relevante, característico do conhecimento nessa seara. Indivíduos dotados de histórias invulgares que os privaram da liberdade e amargando todas as consequências dessa privação em seus contextos pessoais, familiares e afetivos suscitam pesquisadores a aproximações e produções singulares (PAIVA, 2012).

A educação prisional representa um lócus de idealização, de embates e da construção da sua própria identidade. E em função dos fatores acima apontados, há um espaço para a formulação de políticas educacionais traçadas em programas de educação não formal em consequência da possibilidade de flexibilidade que está oferece, especialmente por meio das seguintes atividades: cursos de distintas durações; cursos de formação profissional inicial e continuada; atividades de leitura, de cultura, de teatro e cinema; e manifestações artísticas na tentativa de arquitetar uma educação emancipatória e democrática (CARVALHO, 2012).

Julião (2012, p.21) investigou programas educacionais e laborativos empreendidos como política de execução penal no país, notadamente no estado do Rio de Janeiro, tendo como objetivo primário "verificar qual o real impacto da educação e do trabalho na reinserção social do apenado".

A educação no cárcere representa uma categoria de educação de adultos que assume o propósito de escolarizar, conceber e preparar indivíduos temporariamente encarcerados para que, após o cumprimento do tempo de restrição da liberdade, sejam capazes de se reinserirem com decoro nos planos social e do trabalho, uma vez que esses indivíduos, majoritariamente, possuem restrita ou nenhuma escolarização (PEREIRA, 2011).

Julião (2012), ao perquirir a atribuição da educação como programa de reinserção social na política de execução penal, desenvolve o argumento que sustenta a hipótese de que, no que tange à ressocialização, a educação pode vir a apropriar-se de papel de destaque, uma vez que, além das vantagens da instrução escolar, o apenado pode vir a integrar-se a um processo de transformação, apto a aperfeiçoar a sua visão de mundo, auxiliando na formação de senso crítico, especialmente convertendo-se na compreensão do valor da liberdade e beneficiando o comportamento na vida carcerária. É nesse contexto que Julião (2012) reitera a importância de se examinarem as políticas públicas de ressocialização praticadas no sistema penitenciário brasileiro, debatendo modelos de projetos, seu desenvolvimento, além da sua eficiência, eficácia e efetividade. 
A LEP vislumbrou a educação para os presos reiterando os princípios constitucionais de que todos fazem jus à educação, por conseguinte, não se está diante de uma mera liberalidade concedida pelo Estado para a pessoa encarcerada, nem sequer deve ser fruto de ações de caridade praticadas por pessoas e instituições beneficentes, uma vez que a educação deve ter o propósito de restituir a cidadania perdida ao indivíduo preso, possibilitando-lhe a dignidade de voltar a ser acolhido de forma isenta perante a coletividade (PEREIRA, 2011).

A expressão "reeducando" é empregada na pesquisa de Vasquez (2011, p.14) na acepção de que "reeducar a pessoa presa é ser educado novamente como tentativa de se modificar ou transformar o comportamento humano.”.

A Educação no Cárcere possibilita o acesso a conhecimentos para aqueles indivíduos que estão presos e viabiliza o desenvolvimento cognitivo e social dessas pessoas, a fim de que elas estejam aptas a se reintegrar à sociedade. Trata-se de uma educação voltada tanto para a escolarização (formação no âmbito do sistema oficial de ensino) como para a profissionalização (formação para o mundo do trabalho) (PEREIRA, 2011).

Admite-se que a educação a distância é uma influente aliada para levar mais conhecimento e capacitação aos internos de modo que estes estejam habilitados a empregar suas mentes e intelecto de modo a gerar novos conhecimentos. Acredita-se também que as ocorrências de aprendizagem elaboradas devam consumir um significativo tempo para que o preso se sinta envolvido com o curso e sua ocupação profissional futura (ARRUDA; MOLIN, 2013).

A empreendedora exploração dos dispositivos da Lei de Diretrizes e Bases da Educação Nacional (LDB) concebe a prisão como seara promissora para a experimentação de inovações no campo da pedagogia que não foram praticadas na rede usual de ensino, a despeito de serem permitidas por lei. A referida liberalidade ostentada pela legislação de ensino não encontra similaridade nem na legislação penal nem na Execução Penal que, no entanto, devem experimentar expressivos reflexos da Educação, notadamente quanto aos regimentos disciplinares e ao desempenho do Conselho da Comunidade e do Patronato. Dentre estas inovações convém destacar a relação Educação/Trabalho, a aptidão técnica e profissional do interno para laborar ainda durante o cumprimento da pena e a integração deste ao projeto de reabilitação penal dentro do próprio cárcere, como são os casos do Monitor de Educação e do Agente Prisional de Saúde (SILVA, MOREIRA, 2012).

A contemporânea modificação da LEP, materializada pela Lei $n^{\circ}$. 12.433/2011, a qual alterou o artigo 126 da LEP, com o propósito de inserir a normatização da remição pelo estudo. Faz-se necessário apontar que a remição da pena pelos estudos foi elogiável em sua intenção, 
mas malfadada nos seus critérios, pois desconsidera os objetivos e metas próprias da Educação e oportuniza a concessão da remição somente pela assiduidade à sala de aula, independentemente de o preso finalizar ou não um ciclo, modalidade ou nível de estudos. Entre as possibilidades evidenciadas pelo PPP e a instrumentalização da remição da pena pelos estudos identifica-se um evidente contrassenso, isto é, distintas instâncias da Educação, da Execução Penal, da Administração Penitenciária e da sociedade civil são reunidas para garantir a oferta da Educação nas prisões, contudo, não há instrumentos que levem o preso ao cumprimento das metas e objetivos da Educação contemplados no PPP (SILVA, MOREIRA, 2012).

Visivelmente, a remição aparenta ser a principal justificativa para a retomada dos estudos e da vida escolar no cárcere. A Lei n ${ }^{\circ}$ 12.433/2011 delibera sobre a remição de parcela do tempo de execução da pena por estudo ou por trabalho. O aludido dispositivo legal institui, no artigo $126(\S 1 \mathrm{o}, \mathrm{I})$, que cada doze horas de frequência escolar, decompostas em no mínimo três dias, viabilizam a remissão de um dia de pena. Adicionalmente, no mesmo artigo 126 (§ 5o) encontra-se prevista que a conclusão do ensino fundamental, médio ou superior pode redundar no acréscimo de 1/3 ao tempo a remir em consequência das horas de estudo. Quando se analisa a Lei $n^{\circ} 12.433 / 2011$, é compreende-se por quais motivos a remição seria recomendada como uma significativa justificativa para o retorno às aulas. As movimentações de educadores que foram praticadas antes da promulgação dessa lei enfatizavam a necessidade de atribuir ao estudo o mesmo destaque conferido à atividade laboral nas unidades prisionais em termos de diminuição da pena. Contudo, a remição da pena por intermédio dos estudos passa a estabelecer uma moeda de troca entre escola e estudantes, manifestando para estes uma conexão utilitarista com o movimento de escolarização (SANTOS; DURAND, 2014).

Estudo empreendido em 2003, Auditores do Tribunal de Contas da União apontaram que os estabelecimentos prisionais no Brasil não foram concebidos para o desenvolvimento de atividades educativas, profissionalizantes e laborativas (NUNES apud VASQUEZ, 2011).

A educação nas unidades prisionais alcança um quantitativo reduzido de presos no Brasil e no restante do mundo. Além disso, aponta que a possibilidade de uma ação concreta de educação escolar nos presídios é atualmente viabilizada, especialmente, pela iniciativa individual dos engajados na tarefa. Tal constatação pode expor um paradoxo, posto que as previsões normativas nos contextos nacional e internacional acerca da temática voltam-se para um movimento de reafirmação permanente da educação enquanto um direito de todos (CRAIDY apud OLIVEIRA 2013). 
O ambiente físico da sala de aula com proporções bem exíguas minora o vínculo interpessoal entre docentes e discentes/presos no decurso do processo ensino-aprendizagem, propiciando, de certa maneira, um clima que desencoraja a atuação destes nos afazeres educativos (VASQUEZ, 2011).

A agudeza de espírito de Leme (2007, p.151) transporta o leitor ao universo prisional, quando se reporta à "cela de aula". O autor em pauta se preocupa em contextualizar a escola situada no interior da prisão, tanto sob a ótica da estrutura de funcionamento, como pelo ponto de vista da educação como fenômeno histórico.

A educação é um componente significativo no processo de ressocialização dos apenados, porém é somente um dos componentes, não quer dizer que seja o principal, uma vez que outras políticas necessitam ser formuladas em prol daqueles indivíduos. Sob esse prisma, o Estado é o tutor da vida desses indivíduos e deve assumir a obrigação de assegurar àqueles indivíduos o rol de direitos a que fazem jus, os quais contemplam a manutenção das integridades física, moral e psíquica, independentemente do crime praticado (PEREIRA, 2011).

$\mathrm{Na}$ conjuntura da pesquisa de Oliveira (2013, p.965), os presos enxergam uma estreita conexão entre a educação escolar e a perspectiva de auferir benefícios dentro do cárcere, como a remição de pena. Adicionalmente, vislumbram que o aprendizado escolar articula-se de modo direto à possibilidade de acesso a uma profissão, à esfera do trabalho, bem como pode concorrer para o reconhecimento pessoal e social em detrimento da mácula do cárcere.

A inquietude gerada pela onipresença dos controles, pelo cunho ilimitado e inalcançável das demandas é contrabalanceada pelas conveniências que o presídio pode disponibilizar aos apenados, isto é, conforme os apenados atendam às exigências do modelo de comportamento prisional, podem obter vantagens, tais como: diminuição da pena (a cada três dias de trabalho o interno reduz um dia de sua pena); mudança de regime; direito a visitas íntimas; e, outros benefícios que, no jogo do poder, a instituição pode disponibilizar para alcançar seus objetivos. Logo, por intermédio da mediação psicológica, a instituição penitenciária identifica um sistema coerente, voltado para a subordinação e para o enquadramento do indivíduo no contex to de uma ordem global estabelecida (LEMOS; MAZZILLI; KLERING, 1998).

A educação no cárcere concorreria para o processo de ressocialização do interno de modo que quando ele sair do cárcere seja capaz de angariar oportunidades mais dignas de (re) integração à sociedade. Sabe-se que se trata ainda de um processo que não se constata na íntegra, uma vez que a educação, em termos práticos, não representa um princípio da fundamentação de reintegração. Ainda não se tem notícia de cursos que capacitem o professor de ensino fundamental e médio para trabalhar em estabelecimentos prisionais. Além disso, não 
há cursos de pedagogia customizados para essa modalidade ou mesmo disciplinas que assegurem, minimamente, a integração dos alunos de pedagogia nas discussões envolvendo a Educação-Pedagogia Social no Cárcere (PEREIRA, 2011).

É primordial a ampliação dos esforços de articulação entre as instituições da administração penitenciária e da educação, reproduzidas em nível macro pelos Ministérios da Justiça e da Educação e em nível micro pelo seu corpo gerencial e técnico, reforçando a incumbência de todos na aplicabilidade do direito à educação e, consequentemente, das diretrizes nacionais (OLIVEIRA 2013).

Existem fundamentadas preocupações acerca da possibilidade de ocorrer com a Educação o mesmo que foi verificado em relação ao trabalho no interior das prisões brasileiras. A remição da pena pelo trabalho funcionou como analogia para se admitir a remição da pena por intermédio dos estudos. O trabalho compulsório para o preso e a remição da pena por intermédio dele como direito não foi bastante para introduzir dentro das prisões brasileiras a cultura do trabalho. Não estimulou a profissionalização da mão de obra do preso e nem tampouco atendeu aos intentos de amealhar um patrimônio para seu usufruto em liberdade nem para a compensação dos danos provocados às suas vítimas. Há embasadas apreensões de que a Educação seja empregada como subterfúgio para redução da superlotação prisional; que se impute a ela o ofício de reduzir a reincidência criminal, a violência, evasões e mortes dentro da prisão e mesmo que seja apta a desestimular a pessoa da carreira criminosa. Dentro da prisão, o papel da Educação deve ser única e exclusivamente o de auxiliar o indivíduo privado da liberdade a aprimorar competências e capacidades para estar em melhores possibilidades de pleitear oportunidades geradas socialmente (SILVA, MOREIRA, 2012).

No que tange à compatibilidade entre trabalho e educação no ambiente prisional, convém destacar que o artigo $8^{\circ}$ da Resolução ${ }^{\circ} 03$ de 2009 do Conselho Nacional de Política Criminal e Penitenciária estabelece que: “... o trabalho prisional, também entendido como elemento de formação integrado à educação, deve ser ofertado em horário e condições compatíveis com as atividades educacionais" (OLIVEIRA, 2013).

A pesquisa de Lemos, Mazzilli e Klering (1998) aponta que a instituição penitenciária prescreve a ressocialização por intermédio do trabalho. Contudo, examinando-se o modo como ela sistematiza esse trabalho, identifica-se nitidamente que aquela instituição não apresenta nenhuma das premissas para que o apenado, por meio do trabalho prisional, tenha capacidade de alcançar a efetiva ressocialização. Distante de favorecer o desenvolvimento pessoal dos apenados, a instituição penitenciária subordina os internos à situação de demasiado esfacelamento emocional, e, por consequência, incrementa o descontrole psíquico daqueles 
indivíduos, conduzindo-os progressivamente a se distanciar das condições primordiais ao ajustamento social daquelas pessoas.

Para Melossi (2006), os baixos salários pagos aos presos são muito convenientes, porque convertem o processo de trabalho em algo singularmente opressivo e instrumentam o trabalhador para a sujeição fora da instituição.

Nesse contexto, convém registrar os achados da pesquisa de Carvalho (2016), atrelados ao fato de que a maior parcela da oferta de trabalho provém de microempresas, cuja conveniência está associada ao não pagamento de encargos como férias, $13^{\circ}$ salário, benefício do Instituto Nacional do Seguro Social (INSS) e Fundo de Garantia do Tempo de Serviço (FGTS), uma vez que o preso não está sujeito ao regime da CLT. São dados aderentes às repercussões da pesquisa de Mello apud Carvalho (2016) no âmbito do sistema prisional da Paraíba, que revela que as atividades predominantes dentro da prisão são de baixa complexidade, com poucas vagas ofertadas e remuneradas com salários ínfimos.

O trabalho prisional verdadeiramente representa elemento de ressocialização e denota condição de equilíbrio. Por intermédio dele, os indivíduos asseguram equilíbrio e melhor condicionamento psicológico, bem como melhor engajamento social. Nessas circunstâncias, o trabalho se reveste de importância capital na conformação da identidade. Contudo, para que esse processo se estabilize, faz-se necessário que a administração penitenciária compreenda que, na relação do indivíduo com o trabalho, afloram dois traços intrínsecos de todos os seres humanos: a ação e a reflexão. Desse modo, para alcançarem os patamares de consciência primordiais à ressocialização, os presos não podem e não devem ser reduzidos a um organismo subordinado ao bombardeamento de estímulos restritores (LEMOS; MAZZILLI; KLERING, 1998).

Em última análise, Da Silva (2016) aponta que, nada obstante representar o trabalho um direito do encarcerado, no âmbito do sistema prisional pátrio, restrita parcela dos internos acede a um emprego remunerado, intra ou extramuros. Adicionalmente, o autor em comento registra que, enquanto dever do apenado, o trabalho, quando rejeitado, acarreta em sanção por falta grave, produzindo reflexos de forma direta na pena, inviabilizando múltiplos direitos. Sob outra perspectiva, enquanto direito do interno, o trabalho não ofertado não produz qualquer sanção para o Estado, mesmo que se manifeste em visível prejuízo ao condenado, posto que deixa de remir sua pena. 


\section{Considerações finais}

O objetivo da presente pesquisa foi empreender a análise da viabilidade da educação e do trabalho como instrumentos de ressocialização de indivíduos encarcerados na região metropolitana do Rio de Janeiro. Sob esse prisma, buscou-se responder a seguinte questão de pesquisa: Em que medida a educação e o trabalho possibilitam a ressocialização daqueles indivíduos?

Os apontamentos realizados ao longo da pesquisa empreendida evidenciam que a educação e o trabalho ainda não se configuram como instrumentos efetivos de ressocialização de apenados. A despeito dos avanços observados na legislação, o arcabouço legal não foi capaz de contemplar as demandas de forma plena. O binômio segurança/disciplina tem sido avaliado como um expressivo obstáculo a ser superado. Os expedientes disciplinares e pedagógicos das instituições prisionais apontam de forma clara o conflito e a contradição entre punição e reeducação. Existe uma visível divergência entre a legislação e a realidade do cárcere. Observam-se situações que apontam para a desvirtuação do trabalho e do estudo no sistema carcerário. A atividade laborativa para os internos deixa de se revestir de um caráter essencialmente pedagógico para atender às demandas de continuidade do próprio sistema. $\mathrm{O}$ trabalho não estimulou a profissionalização da mão de obra do preso, não introduziu, naquele contexto, a cultura do trabalho e nem tampouco viabilizou que o interno amealhasse um singelo patrimônio para a vida em liberdade. A remição da pena por intermédio dos estudos passa a estabelecer uma moeda de troca entre escola e estudantes, manifestando uma conexão utilitarista. Não se tem notícia de cursos que capacitem o professor de ensino fundamental e médio para trabalhar em estabelecimentos prisionais e não há cursos de pedagogia customizados para essa modalidade. Enfim, há um longo caminho a ser percorrido.

São constatações que fomentam reflexão e remetem aos escritos de Carnelutti (2013, p.90), o qual afirma que, "enquanto a medicina do corpo alcançou progressos maravilhosos, a medicina do espírito está ainda em um estado infantil..”.

A principal limitação deste estudo está relacionada à metodologia essencialmente pautada em pesquisa bibliográfica. A exiguidade de tempo disponível e os ritos burocráticos autorizativos no âmbito da Secretaria de Administração Penitenciária do Rio de Janeiro inviabilizaram a adoção de uma pesquisa de campo, o que poderia propiciar um resultado mais robusto e consistente. 
Nesse contexto, espera-se que o presente estudo possa favorecer, ainda que de forma introdutória, as discussões sobre ressocialização de indivíduos encarcerados a partir das ações empreendidas pela educação e pelo trabalho no ambiente prisional, permitindo a articulação entre profissionais das searas da administração penitenciária, da educação e da sociedade civil. Sob esse prisma, vislumbra-se que o presente trabalho possa ser desdobrado em questionamentos e investigações futuras, especialmente em outras unidades da federação ou até mesmo em âmbito nacional.

\section{Referências}

ARRUDA, Agnes Marion Mazer; MOLIN, Beatriz Helena Dal. Educação a distância: em novos horizontes para o sistema prisional. Revista Travessias, Cascavel, v.7, n.1, p.232-240, 2013.

CARNELUTTI, Francesco. As misérias do processo penal. Tradução Jeremy Lugros. $1^{\text {a }}$ ed. São Paulo: Editora Nilobook, 2013. 112p.

CARVALHO, Odair França de; GUIMARÃES, Selva. A educação escolar prisional no Brasil sob ótica multicultural: identidade, diretrizes legais e currículos. Horizontes, v. 31, n.2, p. 4957, 2013.

CARVALHO, Odair França de. A educação escolar prisional no Brasil: identidade, diretrizes legais e currículo. Interfaces da Educação, Paranaíba, v.3, n.9, p.94-105, 2012.

CARVALHO, Odair França de. A educação que leva ao trabalho - o trabalho que leva à escola: superando a dicotomia entre educação e trabalho. Cad. CEDES, Campinas, v.36, n.98, p.79-97, 2016.

DA SILVA, José Adaumir Arruda da Silva. A privatização de presídios: uma ressocialização perversa. 1.ed. Rio de Janeiro: Revan, 2016. 164p.

GOFFMAN, Erving. Manicômios, prisões e conventos. Tradução Dante Moreira Leite. 8. ed. São Paulo: Perspectiva, 2008.

JULIÃO, Elionaldo Fernandes. Sistema penitenciário brasileiro: política de execução penal. Petrópolis, RJ: De Petrus et Alii; Rio de Janeiro: FAPERJ, 2012, 408p.

JULIÃO, Elionaldo Fernandes. Ressocialização através da educação e do trabalho no Sistema Penitenciário Brasileiro. Tese (Doutorado). Universidade do Estado do Rio de Janeiro. Instituto de Filosofia e Ciências Humanas, 2009, 440p.

JULIÃO, Elionaldo Fernandes. As políticas de educação para o sistema penitenciário brasileiro: análise de uma experiência brasileira. In: Elenice Onofre. (Org.). Educação Escolar entre as grades. 1ed. São Carlos: EdUFSCar, 2007, v. 1, p. 29-50.

LEME, José Antonio Gonçalves. A cela de aula: tirando a pena com letras. Uma reflexão sobre o sentido da educação nos presídios. In: Elenice Onofre. (Org.). Educação Escolar entre as grades. 1ed. São Carlos: EdUFSCar, 2007, v. 1, p. 111-160. 
LEMOS, Ana Margarete; MAZZILLI, Cláudio; KLERING, Luís Roque. Análise do Trabalho Prisional: um Estudo Exploratório. Rev. Adm. Contemp., v.2, n.3, Curitiba, Set/Dez. 1998.

MELOSI, Dario. A gênese da instituição carcerária moderna. In: MELOSI, Dario; PAVARINI, Massimo. Cárcere e fábrica: As origens do sistema penitenciário (séculos XVI-XIX). Tradução: Sérgio Lamarão. Rio de Janeiro: Instituto Carioca de Criminologia, 2006, p.29-127.

MODONA, Guido Neppi. Apresentação. In: MELOSI, Dario; PAVARINI, Massimo. Cárcere e fábrica: As origens do sistema penitenciário (séculos XVI-XIX). Tradução: Sérgio Lamarão. Rio de Janeiro: Instituto Carioca de Criminologia, 2006, p.11-18.

OLIVEIRA, Carolina Bessa Ferreira de. A educação escolar nas prisões: uma análise a partir das representações dos presos da penitenciária de Uberlândia (MG). Educação e Pesquisa (USP. Impresso), v. 39, p. 955-968, 2013.

PAIVA, Jane. Prefácio. In: JULIÃO, Elionaldo Fernandes. Sistema penitenciário brasileiro: Política de execução penal. Petrópolis, RJ: De Petrus et Alii; Rio de Janeiro: FAPERJ, 2012.

PEREIRA, Antonio. Educação-Pedagogia no Carcere no contexto da Pedagogia Social: definições conceituais e epistemológicas. Revista de Educação Popular (Impresso), v. 10, p. 38-55, 2011.

PORTUGUES, Manoel Rodrigues. Educação de Adultos Presos: possibilidades e contradições da inserção da educação escolar nos programas de reabilitação do Sistema Penal do Estado de São Paulo. Dissertação (Mestrado). Programa de Pós-graduação em Educação. Universidade de São Paulo (USP). São Paulo, 2001.

RIBEIRO, Nilva Ferreira. A prisão na perspectiva de Michel Foucaut. In: LOURENÇO, Arlindo da Silva; ONOFRE, Elenice Maria Cammarosano (Org.). O espaço da prisão e suas práticas educativas: enfoques e perspectivas contemporâneas. São Carlos: EdUFSCar, 2011, p.35-47.

SANTOS, Pollyana dos; DURAND, Olga Celestina da Silva. A Educação de Jovens e Adultos no Espaço Prisional: sentidos da escolarização para mulheres em privação de liberdade. Perspectiva, Florianópolis, v. 32, n. 1, 129-159, jan./abr. 2014.

SILVA, Roberto da. A eficácia sócio pedagógica da pena da privação da liberdade. Tese (Doutorado). Programa de Pós-graduação em Educação. Universidade de São Paulo (USP). São Paulo, 2001.

SILVA, Roberto da; MOREIRA, Fábio Aparecido. Educação em prisões: apontamentos para um projeto político pedagógico. In: $4^{\circ}$ Congresso Internacional de Pedagogia Social, 2012, São Paulo. Proceedings online... Associação Brasileira de Educadores Sociais. 11p.

VASQUEZ, Eliane Leal. Educação Prisional no Brasil: Discursos, práticas e culturas. In: LOURENÇO, Arlindo da Silva; ONOFRE, Elenice Maria Cammarosano (Org.). O espaço da prisão e suas práticas educativas: enfoques e perspectivas contemporâneas. São Carlos: EdUFSCar, 2011, p. 11-33. 